\title{
Pressures and Oscillation Frequencies Generated by Bubble-Positive Expiratory Pressure Devices
}

\author{
Mary D Santos MSc PT, Maree A Milross PhD PT, John P Eisenhuth MSc, and \\ Jennifer A Alison PhD PT
}

\begin{abstract}
BACKGROUND: Positive expiratory pressure (PEP) devices are used to assist with airway clearance. Little is known about the therapist-made or commercially available bubble-PEP devices. The aim of this study was to determine the end-expiratory pressures $\left(\mathrm{cm} \mathrm{H}_{2} \mathrm{O}\right)$ and oscillation frequencies $(\mathrm{Hz})$ generated when a range of flows were applied to the therapist-made bubble-PEP devices (Bubble-PEP-3cm and Bubble-PEP-0cm) and commercial bubble-PEP devices (AguaPEP, Hydrapep, and Therabubble). METHODS: This was a bench-top experimental study using a compressed air source, flow rotameter (flows of 5, 10, 15, 20, and $25 \mathrm{~L} / \mathrm{min}$ ), and pressure transducer. Data were collected using a data acquisition device with PhysioDAQxs software and analyzed with Breathalyser software to determine the pressures and oscillation frequencies generated by 5 bubble-PEP devices. Each flow was constant for a 30-s measurement period, and measurements were repeated in triplicate. The 5 devices were: a therapist-made Bubble-PEP-3cm device (filled with $13 \mathrm{~cm}$ of water, tubing resting $3 \mathrm{~cm}$ from the base of the container); the therapist-made Bubble-PEP- $0 \mathrm{~cm}$ (filled with $10 \mathrm{~cm}$ of water, tubing resting at the base of the container); and the AguaPEP, Hydrapep, and Therabubble devices with water to the $10 \mathrm{~cm}$ mark on the containers. RESULTS: Flows of 5-25 L/min produced the following mean \pm SD PEP and oscillation frequencies $(\mathrm{Hz})$ : the BubblePEP-3cm produced PEP of $10.4 \pm 0.14$ to $10.8 \pm 0.24 \mathrm{~cm} \mathrm{H}_{2} \mathrm{O}$, oscillations between 13 and $17 \mathrm{~Hz}$; the Bubble-PEP-0cm produced PEP of $10.9 \pm 0.01$ to $12.9 \pm 0.08 \mathrm{~cm} \mathrm{H}_{2} \mathrm{O}$, oscillations between 12 and $14 \mathrm{~Hz}$; the AguaPEP produced PEP from $9.7 \pm 0.02$ to $11.5 \pm 0.02 \mathrm{~cm} \mathrm{H}_{2} \mathrm{O}$, oscillations between 11 and $17 \mathrm{~Hz}$; the Hydrapep produced PEP of $9.6 \pm 0.35$ to $10.7 \pm 0.39 \mathrm{~cm} \mathrm{H}_{2} \mathrm{O}$, oscillations between 14 and $17 \mathrm{~Hz}$; and the Therabubble produced PEP from $8.6 \pm 0.01$ to $12.8 \pm 0.03 \mathrm{~cm} \mathrm{H}_{2} \mathrm{O}$, oscillations between 14 and $17 \mathrm{~Hz}$. CONCLUSIONS: Bubble-PEP-3cm maintained the most stable pressure throughout the range of flows tested. All devices investigated produced similar oscillation frequencies. Key words: airway clearance; AguaPEP; bubble; Hydrapep; physiotherapy; positive expiratory pressure device; therapist-made; Therabubble. [Respir Care 2017;62(4):444-450. (C) 2017 Daedalus Enterprises]
\end{abstract}

\section{Introduction}

Positive expiratory pressure (PEP) devices have been used as an airway clearance technique to treat people with respiratory impairments. ${ }^{1-3}$ The rationale for use is that the

\footnotetext{
The authors are affiliated with Clinical and Rehabilitation Sciences, University of Sydney, Lidcombe, New South Wales 2141, Australia. Ms Santos is also affiliated with the Department of Physiotherapy, Prince of Wales Hospital, Barker Street, Randwick, New South Wales 2031, Australia. Ms Alison is affiliated with the Department of Physiotherapy, Royal Prince Alfred Hospital, Missenden Road, Camperdown, New South Wales 2050, Australia.
}

PEP generated when exhaling through the resistor in the device may prevent compression-induced airway collapse by splinting airways open during expiration, which may assist in airway clearance. ${ }^{4}$ PEP may also increase collat-

\footnotetext{
This work was supported by the University of Sydney Postgraduate Research Support Scheme for conference presentation. The authors have disclosed no conflicts of interest.

Ms Santos presented a previous version of this paper at the 11th Cystic Fibrosis Australasian Conference, held August 15-18, 2015, in Sydney, Australia and at the Australian Physiotherapy Association Conference, held October 3-6, 2015, in Gold Coast, Australia.
} 
eral ventilation between adjacent alveoli, ${ }^{5}$ and the increased gas pressure distal to the retained secretions could assist in airway clearance. ${ }^{6}$

A particular type of device that is used to deliver oscillatory PEP is the bubble-PEP device, which is constructed from a container filled with water, with tubing inserted into the container. PEP is generated at the mouth due to the resistance caused by blowing into the water. ${ }^{7}$ A previous study concluded that the PEP generated was dependent on the inner diameter (ID) of the tubing, the diameter of the air escape orifice, and the height of the water column within the tubing. ${ }^{8}$ To generate pressures equal to the height of the water column within the tubing, the tubing ID and diameter of the air escape orifice should be $\geq 8 \mathrm{~mm}^{8}$ so that the only resistance to air flow is that caused by the water column (ie, a threshold resistor device).

In Australia, different bubble-PEP devices are available. These include the therapist-made bubble-PEP device, ${ }^{9}$ which is made from inexpensive and easily accessible materials consisting of a container (eg, bottle) and tubing, and the commercially available devices AguaPEP (PhysiotherapyDynamics Pty Ltd, Queensland, Australia), Hydrapep (Resolve Healthcare, Queensland, Australia), and Therabubble (Physiotherapy Innovations, Queensland, Australia) (Fig. 1), which also consists of a container with water and tubing. However, little is known regarding the pressures and oscillation frequencies generated by these devices. The objective of this study was to determine the end-expiratory pressures and oscillation frequencies generated with flows of $5,10,15,20$, and $25 \mathrm{~L} / \mathrm{min}$ using the therapist-made bubble-PEP devices Bubble-PEP-3cm and Bubble-PEP-0 $\mathrm{cm}$ and the commercial devices AguaPEP, Hydrapep, and Therabubble.

\section{Methods}

This independent laboratory study was conducted at the Faculty of Health Sciences, University of Sydney, Australia.

\section{Equipment Set-Up}

Air flow was supplied by a compressed air source with an attached regulator that could be adjusted to vary the flow applied to the system. Air flowed to a rotameter (Fisher Controls 2000, Fisher Controls Ltd, Croydon, UK), which was used to adjust the flow to the PEP devices.

Correspondence: Mary D Santos MSc PT, Department of Physiotherapy, Prince of Wales Hospital, Barker Street, Randwick, New South Wales 2031, Australia. E-mail: mary.santos@health.nsw.gov.au.

DOI: $10.4187 /$ respcare. 05164

\section{QUICK LOOK}

\section{Current knowledge}

Positive expiratory pressure (PEP) devices are proposed to assist secretion clearance in the lungs by PEP reducing early airway closure and thereby allowing continued expiratory air flow, and by aiding collateral alveolar ventilation which improves alveolar volume distal to the retained secretions, thus assisting clearance to move secretions centrally. Bubble-PEP devices are simple devices constructed from a container filled with water and tubing inserted into the container. A person blows into the tubing to create bubbles in the water, which generates oscillations, and the resistance caused by blowing through the tube into the water generates PEP at the mouth.

\section{What this paper contributes to our knowledge}

We evaluated PEP and oscillations generated by various expiratory flows $(5-25 \mathrm{~L} / \mathrm{min})$ of 5 bubble-PEP devices (therapist-made Bubble-PEP-3cm and Bubble-PEP-0 $\mathrm{cm}$ and commercial bubble-PEP devices AquaPEP, Hydrapep, and Therabubble). The Bubble-PEP-3cm had the most stable PEP (ie, minimal change in PEP with increasing flow), whereas the Therabubble had the most variable PEP. All PEP devices investigated produced oscillation frequencies between 11 and $17 \mathrm{~Hz}$.

Flows delivered were $5,10,15,20$, and $25 \mathrm{~L} / \mathrm{min}$. These flows were chosen to represent possible flows generated by patients, since mean expiratory flow in healthy subjects is approximately $18-19 \mathrm{~L} / \mathrm{min}^{8}{ }^{8}$ From the rotameter, air flow passed through a pneumotachometer heated to $37^{\circ} \mathrm{C}$ (Hans Rudolph Heater Control Series 3850A, Hans Rudolph, Shawnee, Kansas). A T-piece from the pneumotachometer was connected to the tubing that was inserted in the bubble-PEP device and to the pressure transducer (Validyne DP45, Validyne Engineering Corp, Northridge, California). Air flowed from the pneumotachometer, through the PEP tubing, and into the water (Fig. 2). The connections in the equipment setup were checked to ensure that there were no air leaks.

\section{Instrumentation Calibration}

The rotameter was calibrated by a flow analyzer (PF300, IMT Medical, Buchs, Switzerland). The pressure transducer was calibrated using a water manometer. Various pressures were applied to the pressure transducer using a syringe. The pressure signal was digitized, and a line of best fit was calculated and used by PhysioDAQxs (Uni- 


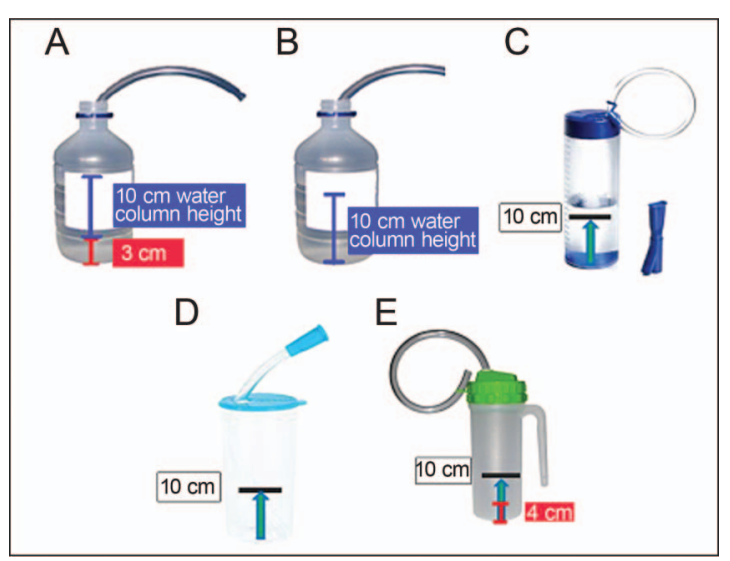

Fig. 1. Picture of bubble PEP devices. A: Bubble-PEP-3cm with water at the $13 \mathrm{~cm}$ mark, tubing resting $3 \mathrm{~cm}$ from the base of the container, and height of water in tubing $10 \mathrm{~cm}$. B: Bubble-PEP$0 \mathrm{~cm}$ with water at the $10 \mathrm{~cm}$ mark, tubing resting at the base of the container, and height of water in tubing $10 \mathrm{~cm}$. C: AguaPEP with water at the $10 \mathrm{~cm}$ mark, tubing resting on the base of the container, and height of water in tubing $10 \mathrm{~cm}$. D: Hydrapep with water at the $10 \mathrm{~cm}$ mark, tubing resting on the base of the container, and height of the water in tubing $10 \mathrm{~cm}$. E: Therabubble with water at the $10 \mathrm{~cm}$ mark, tubing resting $4 \mathrm{~cm}$ from the base of the container, and height of water in tubing $6 \mathrm{~cm}$.

versity of Sydney, Australia) to scale the signal to units of $\mathrm{cm} \mathrm{H}_{2} \mathrm{O}$. The pressure transducer was calibrated before every experiment.

\section{Devices}

Figure 1 shows the 5 bubble-PEP devices investigated in this study, and Table 1 presents the characteristics of these devices. The construction of the therapist-made bubble-PEP devices was based on a survey that investigated the most common way physiotherapists in Australia constructed this device. ${ }^{9}$ The therapist-made Bubble-PEP- $3 \mathrm{~cm}$ device consisted of a polyvinyl chloride compound container, which had a height of $21 \mathrm{~cm}$ and a width of $10 \mathrm{~cm}$ (Baxter Steri-Pour Bottle, Baxter Healthcare Pty Ltd, New South Wales, Australia), and polyethylene tubing (SMC Corporation of America, Noblesville, Indiana) with an ID of $10 \mathrm{~mm}$ and length of $30 \mathrm{~cm}$, with the distal end of the tubing resting $3 \mathrm{~cm}$ from the base of the container (ie, the Bubble-PEP-3 $\mathrm{cm}$ device container was filled with water to a height of $13 \mathrm{~cm}$ with a consequent water column height in the tubing of $10 \mathrm{~cm}$ ). The therapist-made Bubble-PEP$0 \mathrm{~cm}$ device was exactly the same as the Bubble-PEP- $3 \mathrm{~cm}$ device except that the distal end of the tubing rested at the base of the container (ie, the Bubble-PEP-0 cm device container was filled with water to a height of $10 \mathrm{~cm}$ with a consequent water column height in the tubing of $10 \mathrm{~cm}$ ). In both therapist-made devices, there was no lid on the container neck through which the tubing passed (ie, the top of the container was open).

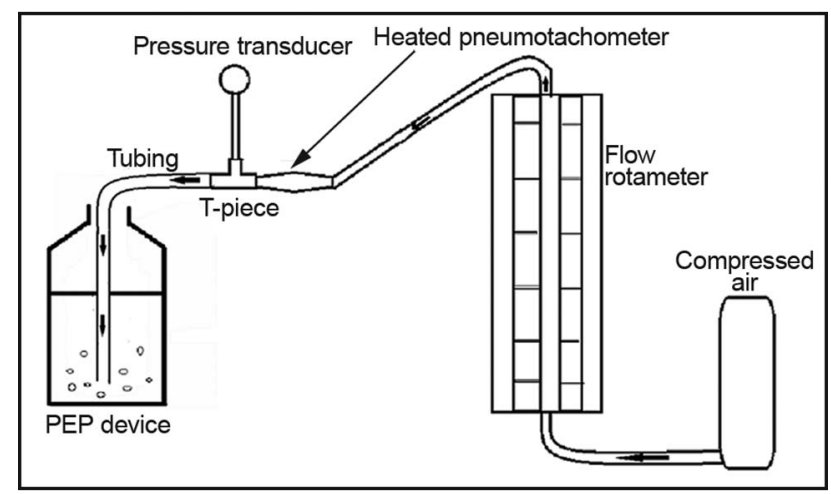

Fig. 2. Experimental setup. Arrows indicate direction of air flow.

The commercially available bubble-PEP devices investigated were the AguaPEP, Hydrapep, and Therabubble. For the commercial devices, water in the container was at the $10 \mathrm{~cm}$ mark indicated on each device.

\section{Data Collection}

Data were collected in a stepwise manner (ie, for each device, flow at $5 \mathrm{~L} / \mathrm{min}$ was constant for a 30 -s measurement period to capture mean pressure and oscillation frequency from the pressure transducer, before progressing to a flow of $10 \mathrm{~L} / \mathrm{min}$ to capture 30 -s measurement data). Flow was increased at increments of $5 \mathrm{~L} / \mathrm{min}$. Once $25 \mathrm{~L} / \mathrm{min}$ was reached and data were collected, measurement began at $5 \mathrm{~L} / \mathrm{min}$ again. The experiment was repeated 3 times at each flow for each device.

The analog signal from the pressure transducer was collected by a data acquisition device (DAQCard 1200, National Instruments Corporation, Austin, Texas) installed on a computer. PhysioDAQxs software running on the computer controlled the capture and display of the pressure data. The data sampling frequency was $150 \mathrm{~Hz}$. Data were saved in text format on the computer's hard disk drive.

Data were analyzed using Breathalyser software (University of Sydney, Australia). Breathalyser opened PhysioDAQxs files and allowed a range of mathematical operations to be performed on the selected data. For analysis of oscillations, Breathalyser counted the number of oscillations in a selected time interval and calculated the frequency of the oscillations. Results were displayed in a table on the computer's monitor and saved as a text file on the computer's hard disk drive.

\section{Statistical Analysis}

Data were analyzed using SPSS 22 (IBM, Armonk, New York). Regression analysis was used to determine the relationship between expiratory pressures and flow. Mean 
Table 1. Device Characteristics

\begin{tabular}{|c|c|c|c|c|c|}
\hline Device & Bubble-PEP-3cm & Bubble-PEP-0cm & AguaPEP* & Hydrapep & Therabubble* \\
\hline \multicolumn{6}{|l|}{ Container } \\
\hline Height, $\mathrm{cm}$ & 20 & 20 & 23.6 & 18 & 23 \\
\hline Diameter of base, $\mathrm{cm}$ & 8.6 & 8.6 & 7.6 & 7.8 & 7.6 \\
\hline Diameter of air escape orifice, $\mathrm{cm}$ & 3 & 3 & 2.4 & 2 & 0.8 \\
\hline \multicolumn{6}{|l|}{ Tubing } \\
\hline Continuous tubing & Yes & Yes & No & Yes & No \\
\hline Length inside container, $\mathrm{cm}$ & 17 & 20 & 20.5 & 18 & 19.2 \\
\hline Length outside container, $\mathrm{cm}$ & 13 & 10 & 30 & 17.2 & 46.5 \\
\hline ID of tubing inside container, $\mathrm{mm}$ & 10 & 10 & 8 & 10 & 9.5 \\
\hline ID of tubing outside container, $\mathrm{mm}$ & 10 & 10 & 8 & 10 & 10 \\
\hline ID of connector between tubing inside and outside container, $\mathrm{mm}$ & NA & NA & 10 & NA & 5 \\
\hline Distance of distal end of tubing from base of container, $\mathrm{cm}$ & 3 & 0 & 0 & 0 & 4 \\
\hline \multicolumn{6}{|c|}{$\begin{array}{l}\text { * The AguaPEP and Therabubble had } 2 \text { separate tubes, internal (inside container) and external (outside container) tubing, joined by a connector that acts as a one-way valve. } \\
\text { ID = inner diameter } \\
\text { NA = not applicable }\end{array}$} \\
\hline
\end{tabular}

values for pressures and frequency of oscillations generated at each flow were calculated from the mean of the means of the 3 measurements. Two-way analysis of variance for repeated measures and independent $t$ tests were used to determine the rate of change in PEP with increasing flow between devices. Differences were considered statistically significant when $P$ was $<.05$.

\section{Results}

\section{Levels of PEP Generated}

Figure 3 shows the effect of flow on PEP generated in the 5 devices investigated. The linear rate of increase in expiratory pressure with every $5 \mathrm{~L} / \mathrm{min}$ increase in flow for each device is shown in Table 2. The smallest increase in pressure with increase in flow was $0.08 \mathrm{~cm} \mathrm{H}_{2} \mathrm{O}$ in the Bubble-PEP- $3 \mathrm{~cm}$ device, and the largest increase in expiratory pressure with increase in flow was $1.06 \mathrm{~cm} \mathrm{H}_{2} \mathrm{O}$ in the Therabubble device. In all devices investigated, flow significantly affected the expiratory pressure generated (Table 2).

Linear regression was used to compare the change in PEP generated with change in flow between the 5 devices (Table 3). Only the Bubble-PEP-0 $\mathrm{cm}$ and AguaPEP were not statistically significantly different from each other $(P=.28)$.

\section{Oscillation Frequency}

All PEP devices investigated generated oscillations during air flow (Fig. 4). For flows between 5 and $25 \mathrm{~L} / \mathrm{min}$, Bubble-PEP- $3 \mathrm{~cm}$ generated oscillation frequencies between 13 and $17 \mathrm{~Hz}$; the Bubble-PEP-0cm generated os- cillation frequencies between 12 and $14 \mathrm{~Hz}$; the AguaPEP generated oscillation frequencies between 11 and $17 \mathrm{~Hz}$; the Hydrapep generated oscillation frequencies between 14 and $17 \mathrm{~Hz}$; and the Therabubble generated oscillation frequencies between 14 and $17 \mathrm{~Hz}$.

\section{Discussion}

This is the first study to compare the therapist-made bubble-PEP devices Bubble-PEP-3cm and Bubble-PEP$0 \mathrm{~cm}$ with the commercially available bubble-PEP devices AguaPEP, Hydrapep, and Therabubble. Bubble-PEP- $3 \mathrm{~cm}$ had the smallest change in expiratory pressure with increasing flow, whereas Therabubble had the largest change in expiratory pressure with increasing flow. When compared with the other devices investigated, the Bubble-PEP$3 \mathrm{~cm}$ produced the most stable expiratory pressure regardless of flow, and the level of expiratory pressure was consistent with the height of the water within the tubing. Thus, Bubble-PEP- $3 \mathrm{~cm}$ could be considered a threshold resistor device (ie, the pressure generated remained constant, and approximately equal to the height of the water column, at any expiratory flow).

All devices investigated had tubing and air escape orifices with ID $\geq 8 \mathrm{~mm}$, which would be expected to generate pressures equal to the height of the water column independent of expiratory flow. ${ }^{8}$ Despite this, there were differences between devices in the expiratory pressures generated. The differences in PEP generated with increasing flow were most likely due to design characteristics of the devices (Table 1), such as the distance of the tubing from the base of the container or the connector joining the internal and external tubings (AguaPEP and Therabubble). Both of these factors could increase pressures. 


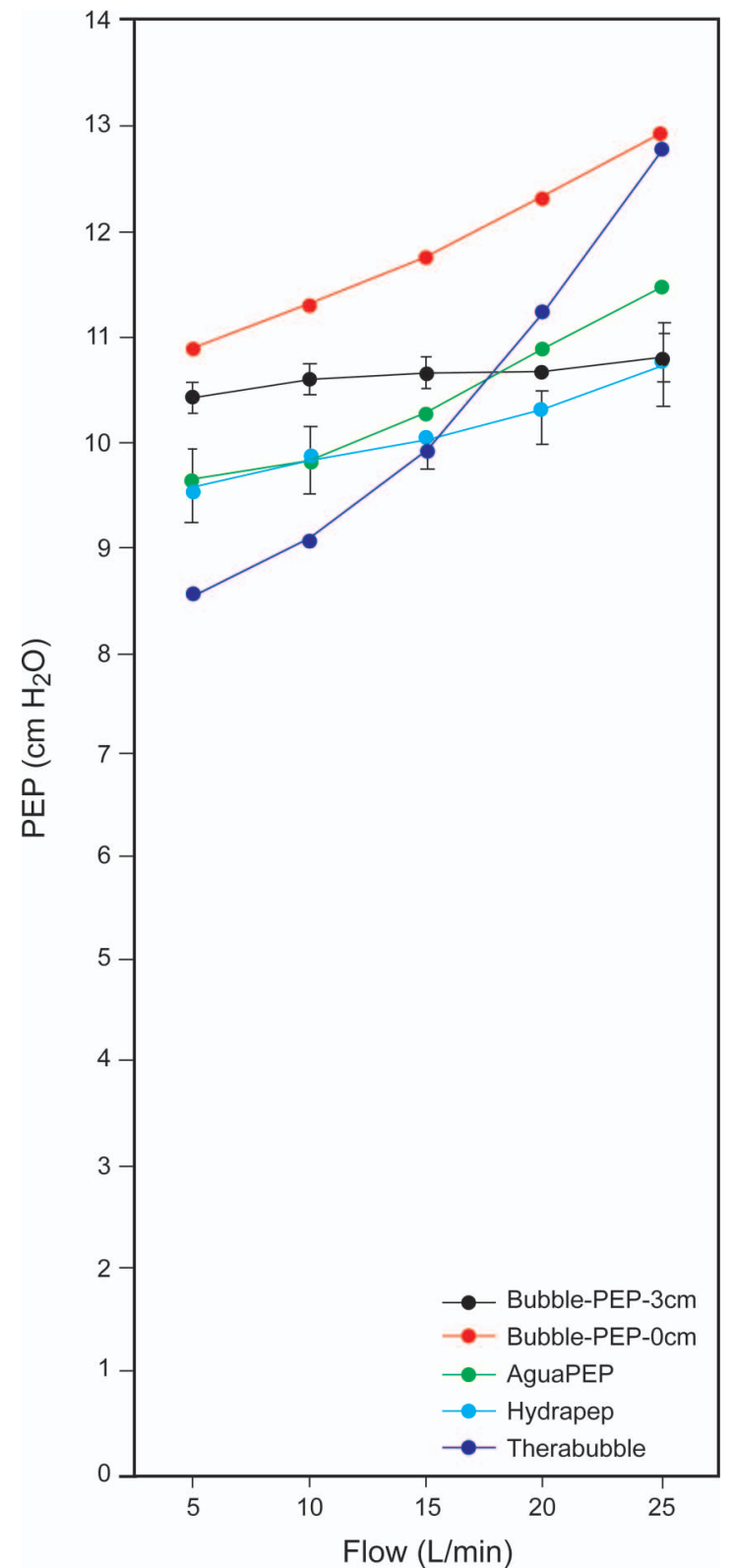

Fig. 3. Flow and positive expiratory pressure (PEP) relationship for Bubble-PEP-3cm, Bubble-PEP-0cm, AguaPEP, Hydrapep, and Therabubble devices. Error bars indicate SD.

To our knowledge, this is the first study to investigate the effect of placement of tubing in the container on the amount of PEP generated. Bubble-PEP- $0 \mathrm{~cm}$ generated higher PEP than Bubble-PEP- $3 \mathrm{~cm}$ at all flows. Although the water height within the tubing in both devices was $10 \mathrm{~cm}$, this was achieved in the Bubble-PEP- $3 \mathrm{~cm}$ by having a water height in the container of $13 \mathrm{~cm}$ with the tubing resting $3 \mathrm{~cm}$ from the base of the container, whereas in the Bubble-PEP- $0 \mathrm{~cm}$, the water height in the container was $10 \mathrm{~cm}$ with the tubing resting on the base of the container. The resistance to air flow into the water at the distal end of the tubing when the tubing rested on the base of the container could have increased the expiratory pressures generated (ie, the base of the container may have increased the resistance to air escaping from the distal end of the tubing, thus increasing the PEP). The Bubble-PEP$0 \mathrm{~cm}$ and Hydrapep had very similar design characteristics, but the Bubble-PEP-0 $\mathrm{cm}$ had consistently higher PEP generated at all flows. The authors hypothesized that the difference in PEP generated between devices may have been due to the type of tubing. The therapist-made Bubble-PEP$0 \mathrm{~cm}$ device had a rigid plastic tubing that did not deviate from its position at the base of the container, thereby providing constant resistance to air flow, whereas the Hydrapep had flexible plastic tubing that was able to deviate its position from the base of the container, thereby providing less resistance to air flow.

The AguaPEP and Hydrapep also had tubing resting at the base of the container, but the AguaPEP had higher pressures than the Hydrapep at flows $>10 \mathrm{~L} / \mathrm{min}$. This was probably due to the connector between the internal (inside the container) and external (outside the container) tubings in the AguaPEP having a smaller ID than the tubing ID, which would increase resistance to air flow and thereby increase the PEP as described by Hagen-Poiseuille's law. This was also true for the Therabubble, where the connector between the 2 tubings had an ID of approximately $5 \mathrm{~mm}$ and was most likely the reason for the demonstrated increase in pressure with increasing flow (Fig. 3). A previous study has shown that if tubing has an ID of $<8 \mathrm{~mm}$, the pressure generated increases with increasing air flow. ${ }^{8}$

Whereas the AguaPEP, Hydrapep, and Therabubble were filled with water to the $10 \mathrm{~cm}$ mark indicated on the devices, the distal end of the Therabubble tubing was $4 \mathrm{~cm}$ from the base of the container, unlike the AguaPEP and Hydrapep, were the distal end of the tubing was at the base of the container. Thus, in the Therabubble, the actual height of the column of water providing resistance to expiration was only $6 \mathrm{~cm}$, which may explain the low pressures generated at a flow of $5 \mathrm{~L} / \mathrm{min}$ in this device. The AguaPEP and Hydrapep did not generate the expected $10 \mathrm{~cm} \mathrm{H}_{2} \mathrm{O}$ pressure at a flow of $5 \mathrm{~L} / \mathrm{min}$ with a $10 \mathrm{~cm}$ water column height, which indicates that flows $>5 \mathrm{~L} / \mathrm{min}$ may be required to generate pressures equal to the height of the water column in these devices.

Although the Bubble-PEP-3cm, Bubble-PEP-0cm, AguaPEP, Hydrapep, and Therabubble generated different expiratory pressures with increasing flow, these differences may not be clinically relevant, since the expiratory pressure generated by all devices ranged from 8 to $13 \mathrm{~cm} \mathrm{H}_{2} \mathrm{O}$. Currently, it is unknown whether such differences would affect the ability of the devices to assist airway clearance. Only a low flow of $5 \mathrm{~L} / \mathrm{min}$ was required to generate PEP of 8-11 $\mathrm{cm} \mathrm{H}_{2} \mathrm{O}$ in the devices investi- 
Table 2. Change in Expiratory Pressure With Increasing Flow for Each Device

\begin{tabular}{|c|c|c|c|c|c|}
\hline Device & Bubble-PEP-3cm & Bubble-PEP-0cm & AguaPEP & Hydrapep & Therabubble \\
\hline Rate of change*, mean $\pm \mathrm{SD} \mathrm{cm} \mathrm{H}_{2} \mathrm{O}$ & $0.08 \pm 0.07$ & $0.51 \pm 0.04$ & $0.48 \pm 0.07$ & $0.28 \pm 0.13$ & $1.06 \pm 0.13$ \\
\hline$P \dagger$ & .02 & $<.001$ & $<.001$ & $<.001$ & $<.001$ \\
\hline
\end{tabular}

Table 3. Statistical Significance of Linear Regression Slopes Between Devices

\begin{tabular}{lcccc}
\hline \hline \multirow{2}{*}{ Device } & \multicolumn{5}{c}{$P$} \\
\cline { 2 - 5 } & Bubble-PEP-3cm & Bubble-PEP-0cm & AguaPEP & Hydrapep \\
\hline Bubble-PEP-0cm & $<.001$ & NA & NA & NA \\
AguaPEP & $<.001$ & .28 & NA & NA \\
Hydrapep & .005 & $<.001$ & .003 & NA \\
Therabubble & $<.001$ & $<.001$ & $<.001$ & $<.001$ \\
& & & & \\
NA = not applicable & & & & \\
\end{tabular}

gated, which may make these PEP devices suitable for people with impaired ability to generate expiratory flow.

All 5 devices investigated produced oscillation frequencies of 11-17 Hz, comparable with those of the Acapella (DHD Healthcare, Wampsville, New York) and Flutter (VarioRaw SA, Aubonne, Switzerland) devices. ${ }^{10-12}$ Oscillation frequencies similar to ciliary beat frequency of 13.2 $\mathrm{Hz}^{13}$ may aid secretion clearance by increasing the amplitude and frequency of the cilia, potentially increasing mucociliary transport. ${ }^{11}$ A study investigating the clearance of mucus in the trachea of dogs found that the enhancement of clearance was most pronounced if the oscillation frequency was between 11 and $15 \mathrm{~Hz},{ }^{14}$ whereas another study investigating the Flutter device in children and adults with cystic fibrosis found that airway oscillations of approximately $19 \mathrm{~Hz}$ reduced sputum viscoelasticity in vitro, ${ }^{15}$ making it easier to move airway secretions. In our study, flow as low as $5 \mathrm{~L} / \mathrm{min}$ produced oscillation frequencies between 11 and $15 \mathrm{~Hz}$. This may make the PEP devices investigated suitable to aid secretion clearance in people with impaired respiratory function.

A limitation of this study was that the tests were done in a laboratory setting and may not be reproducible in a clinical setting with human participants. However, this study clarifies the pressures and oscillations that are generated with a range of flows in these clinically available PEP devices.

The PEP generated by these bubble-PEP devices may splint airways open during expiration, thereby preventing early airway closure. ${ }^{4}$ PEP may also promote movement of air through collateral channels, enabling air to enter

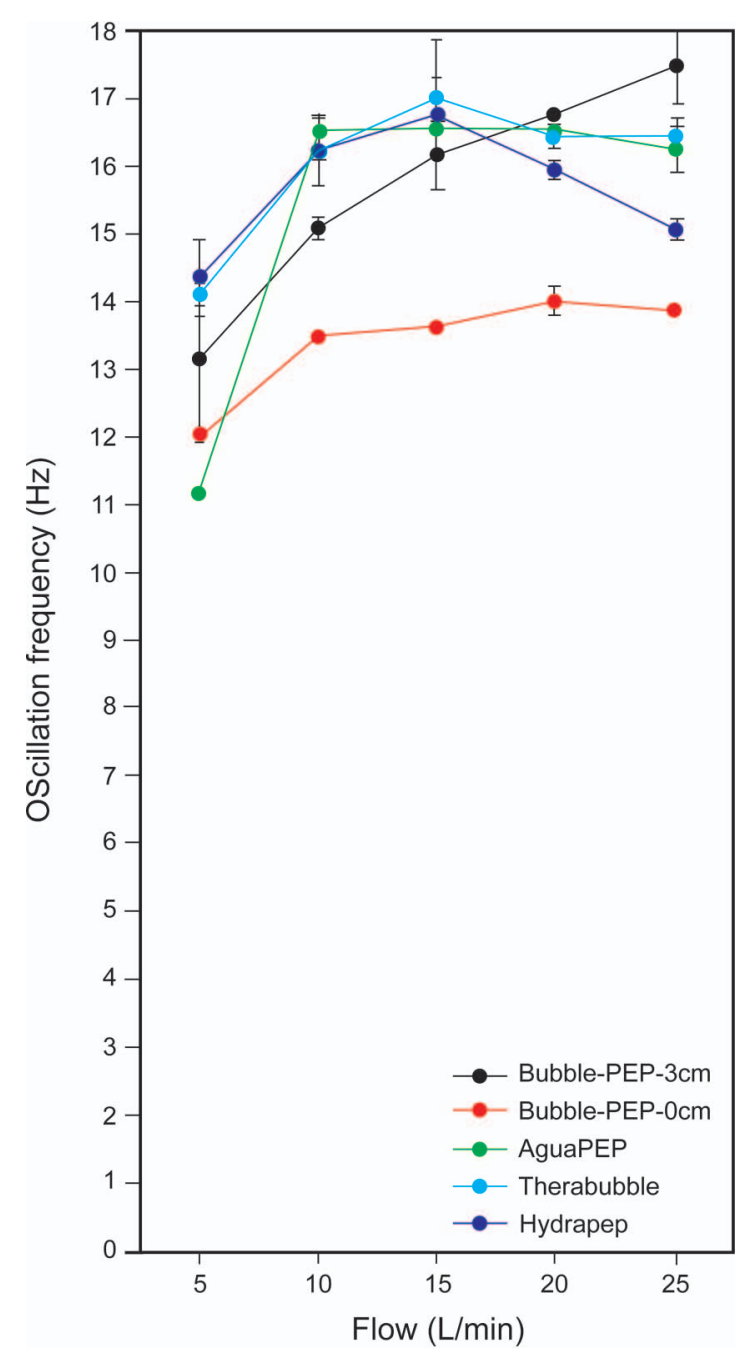

Fig. 4. Oscillation frequency in relation to flow for each bubblepositive expiratory pressure (PEP) device. Error bars indicate SD.

alveoli distal to the retained secretions, potentially aiding secretion clearance by expiratory air flow. ${ }^{6}$ The oscillations produced by the devices investigated may improve secretion clearance through the effect on mucociliary transport and sputum viscoelasticity. The particular design of Bubble-PEP- $3 \mathrm{~cm}$ in this study showed that the PEP generated was equal to the height of the water column in the tubing regardless of flow and that only a low flow of $5 \mathrm{~L} / \mathrm{min}$ is required to generate $10 \mathrm{~cm} \mathrm{H}_{2} \mathrm{O}$ PEP and os- 


\section{PEP Pressures and Oscillation Frequencies}

cillation frequency of $13 \mathrm{~Hz}$ required to aid airway clearance. Because the therapist-made Bubble-PEP- $3 \mathrm{~cm}$ can be constructed from easily attainable and inexpensive materials, this PEP device provides a cheaper alternative than commercially available PEP devices and may be more attainable for people with limited health-care resources.

\section{Conclusions}

Design characteristics of PEP devices can influence the pressures generated. Bubble-PEP-3cm maintained the most stable PEP with increasing flows compared with the other PEP devices tested and could therefore be considered a threshold resistor device. Although there was some variability in the pressures generated between Bubble-PEP$3 \mathrm{~cm}$, Bubble-PEP-0 $\mathrm{cm}$, AguaPEP, Hydrapep, and Therabubble devices with increasing flows, the size of the pressure differences was small and may not be clinically relevant. All PEP devices investigated produced oscillation frequencies between 11 and $17 \mathrm{~Hz}$, which could aid secretion clearance. Further research is warranted to determine the effects of these devices in people with respiratory impairments. The actual PEP and oscillation frequency required for optimal airway clearance in patient populations also need further investigation.

\section{ACKNOWLEDGMENTS}

We thank Professor Jenny Peat for contributions to statistical analysis.

\section{REFERENCES}

1. O'Neill B, Bradley JM, McArdle N, MacMahon J. The current physiotherapy management of patients with bronchiectasis: a UK survey. Int J Clin Pract 2002;56(1):34-35.

2. Lee A, Button B, Denehy L. Current Australian and New Zealand physiotherapy practice in the management of patients with bronchiectasis and chronic obstructive pulmonary disease. NZ J Physiother 2008;36(2):49-58.
3. Johnston CL, James R, Mackney JH. The current use of positive expiratory pressure (PEP) therapy by public hospital physiotherapists in New South Wales. N Z J Physiother 2013;41(3) 88-93.

4. Oberwaldner B, Evans JC, Zach MS. Forced expirations against a variable resistance: a new chest physiotherapy method in cystic fibrosis. Pediatr Pulmonol 1986;2(6):358-367.

5. Andersen JB, Qvist J, Kann T. Recruiting collapsed lung through collateral channels with positive end-expiratory pressure. Scand J Respir Dis 1979;60(5):260-266.

6. Groth S, Stafanger G, Dirksen H, Andersen JB, Falk M, Kelstrup M. Positive expiratory pressure (PEP-mask) physiotherapy improves ventilation and reduces volume of trapped gas in cystic fibrosis. Bull Eur Physiopathol Respir 1985;21(4):339-343.

7. Sehlin M, Ohberg F, Johansson G, Winsö O. Physiological responses to positive expiratory pressure breathing: a comparison of the PEP bottle and the PEP mask. Respir Care 2007;52(8):1000-1005.

8. Mestriner RG, Fernandes RO, Steffen LC, and Donadio MVF. Optimum design parameters for a therapist-constructed positive-expiratory-pressure therapy bottle device. Respir Care 2009;54(4):504508.

9. Santos MD, Milross MA, Alison JA. Therapist-made bubble-positive expiratory pressure: a survey of physiotherapists in Australia. Cardiopulm Phys Ther J 2016;27:3-10.

10. Volsko TA, DiFiore J, Chatburn RL. Performance comparison of two oscillating positive expiratory pressure devices: acapella versus flutter. Respir Care 2003;48(2):124-130.

11. McCarren B, Alison JA. Physiological effects of vibration in subjects with cystic fibrosis. Eur Respir J 2006;27(6):1204-1209.

12. Mueller G, Bersch-Porada I, Koch-Borner S, Raab AM, Jonker M, Baumberger M, Michel F. Laboratory evaluation of four different devices for secretion mobilization: acapella choice, green and blue versus water bottle. Respir Care 2014;59(5):673-677.

13. Chilvers MA, O'Callaghan C. Analysis of ciliary beat pattern and beat frequency using digital high speed imaging: a comparison with the photomultiplier and photodiode methods. Thorax 2000;55(4): 314-317.

14. King M, Phillips DM, Gross D, Vartian V, Chang HK, Zidulka A. Enhanced tracheal mucus clearance with high frequency chest wall compression. Am Rev Respir Dis 1983;128(3):511-515.

15. App EM, Kieselmann R, Reinhardt D, Lindemann H, Dasgupta B, King M, Brand P. Sputum rheology changes in cystic fibrosis lung disease following two different types of physiotherapy: flutter vs autogenic drainage. Chest 1998;114(1):171-177. 